\title{
The influence of various therapeutic regimens on early clinical and laboratory response and outcome of children with secondary hemophagocytic lymphohistiocytosis
}

\author{
Piotr Buda ${ }^{1}$, Piotr Gietka², Janusz B. Książyk ${ }^{1}$, Maciej Machaczka³
}

\author{
${ }^{1}$ Department of Pediatrics, The Children's Memorial Health Institute, Warsaw, Poland \\ 'Eleonore Reicher's Rheumatology Institute, Warsaw, Poland \\ ${ }^{3}$ Department of Medicine, Karolinska Institutet, Karolinska University Hospital \\ Huddinge, Stockholm, Sweden
}

Submitted: 14 September 2015

Accepted: 15 November 2015

Arch Med Sci 2018; 14, 1: 138-150

DOI: 10.5114/aoms.2015.56325

Copyright (c) 2016 Termedia \& Banach

\section{Abstract}

Introduction: Secondary hemophagocytic lymphohistiocytosis (sHLH) is a life-threatening syndrome of severe hyperinflammation which is often triggered by infection or autoimmune disease (macrophage activation syndrome - MAS). The aim of our study was to assess the frequency of sHLH/ MAS in children treated in our institution and to compare the effectiveness of various therapeutic interventions.

Material and methods: Between 2005 and 2013, 24 children (age: 1-17 years) were consecutively treated for SHLH/MAS. Therapy was based on glucocorticoids (GCs) in high or standard doses (hd-GCs or sd-GCs), intravenous immunoglobulin (IVIG), and cyclosporin A (CyA). A comparison of selected laboratory and clinical parameters during the first $72 \mathrm{~h}$ of treatment and after a week from the last intervention applied in the first $72 \mathrm{~h}$ after diagnosis was performed retrospectively.

Results: The majority of patients $(14 / 24,58 \%)$ suffered from sHLH/MAS in the course of an autoimmune disease (12 patients diagnosed with a systemic form of juvenile idiopathic arthritis). We found with a confidence level of $95 \%$ that the application of hd-GCs in the first $24 \mathrm{~h}$ caused rapid alleviation of fever, reduction of hepatosplenomegaly, and an increase in thrombocytes and s-fibrinogen concentrations. The use of combination therapy with hdGCs, IVIG, and CyA in the first $72 \mathrm{~h}$ caused a faster increase in s-fibrinogen. All patients survived and were alive at the follow-up of 1-8 years.

Conclusions: The results indicate that treatment of SHLH/MAS based on hdGCs, CyA and IVIG is an effective therapy in children.

Key words: hemophagocytic lymphohistiocytosis, macrophage activation syndrome, juvenile idiopathic arthritis, children.

\section{Introduction}

Hyperinflammatory syndromes caused by massive cytokine release from activated immune cells in response to various congenital and acquired factors encompass an infrequent, yet potentially life-threatening group of disorders [1, 2]. Macrophages and cytotoxic CD8+ lymphocytes massively release various inflammatory mediators (e.g., INF- $\gamma$, TNF- $\alpha$,

\author{
Corresponding author: \\ Piotr Buda MD \\ Department of Pediatrics \\ The Children's Memorial \\ Health Institute \\ Al. Dzieci Polskich 20 \\ 04-730 Warsaw, Poland \\ Phone: +48228151410 \\ E-mail: piotrbuda@gmail.com
}


IL-1, IL-6), and hematopoietic growth factors [3, 4]. Aforementioned phenomena together with impaired cytotoxic function of natural killer (NK) cells and CD8+ lymphocytes results in the hyperinflammatory phenotype [1].

The clinical syndrome of the exaggerated inflammatory reaction is called hemophagocytic lymphohistiocytosis (HLH) or hemophagocytic syndrome [1]. Depending on the etiology, HLH can be divided into genetic and acquired (secondary $\mathrm{HLH}-\mathrm{sHLH}$ ) forms [1, 2, 5]. Inherited forms of HLH usually present in infancy or early childhood ( $80 \%$ of cases). Secondary HLH develops at any age as a consequence of immune activation caused by infection, autoimmune disorder or malignancy $(\mathrm{I}-\mathrm{HLH}, \mathrm{A}-\mathrm{HLH}$ or M-HLH) [5-7].

The hyperinflammatory response may be the cause of long-lasting unexplained fever [1]. Besides fever, the most common symptoms of $\mathrm{HLH}$ are splenomegaly and peripheral blood cytopenia $[1,5]$. Hepatomegaly, lymphadenopathy, neurological symptoms, edema or skin rash may also be present. Biochemical hallmarks of HLH include hyperferritinemia, increased level of the $\alpha$ chain of the soluble receptor for interleukin-2 (sIL-2R $\alpha$; SCD25), hypertriglyceridemia, hypofibrinogenemia, coagulopathy, hyponatremia, and elevated liver transaminases and bilirubin [3]. High levels of SIL-2R $\alpha$ in serum are seen in all forms of $\mathrm{HLH}$ [5]. Although sIL-2R $\alpha$ and hyperferritinemia are markers of generalized inflammation, ferritin levels $>3000 \mu \mathrm{g} / \mathrm{l}$ raise suspicion for $\mathrm{HLH}$, and levels $>10,000 \mu \mathrm{g} / \mathrm{l}$ are highly suspicious [8]. Cytohistological examination of the affected tissues may reveal hemophagocytosis [1].

Mechanisms of acquired HLH are not completely understood. Some patients have at least transient defects in NK cell function or have a single copy of a known gene mutation in $\mathrm{HLH}[9,10]$. Recent studies in animal models suggest enhanced antigen presentation and excessive signaling of Toll-like receptors as mechanisms of SHLH [11].

Autoimmune-associated $\mathrm{HLH}$, often referred to by many rheumatologists as macrophage activation syndrome (MAS), has most often been reported in the systemic form of juvenile idiopathic arthritis (7-10\% of patients) but can also occur in the course of other autoimmune diseases [11-13]. A-HLH/MAS may present as a life-threatening disease; symptoms are often difficult to distinguish from an exacerbation of the patient's underlying autoimmune disease or triggering infection, which increases the risk of delaying diagnosis and appropriate therapy [12-15].

So far, treatment of A-HLH/MAS is not standardized and remains highly variable across clinical centers [16]. A frontline treatment of MAS, particularly of milder grades, involves glucocorti- coids with or without intravenous immunoglobulin (IVIG), which may be sufficient to control hyperinflammation [13]. Immunochemotherapy (including etoposide) based on the protocol HLH-2004 has an associated 5-year mortality of $54 \%$ of patients, and it is believed that it may favorably affect the outcome in severe cases of SHLH/MAS [1].

The aim of our study was to assess the frequency of SHLH/MAS in children treated in our institution for non-malignant SHLH and to compare the effectiveness of various therapeutic interventions.

\section{Material and methods}

The study population includes 24 children aged 1-17 years, who were consecutively treated for non-malignant secondary $\mathrm{HLH}$ at the Department of Pediatrics, the Children's Memorial Health Institute in Warsaw, between January 2005 and December 2013. All patients were referred with the following indications: generalized inflammatory reaction of unknown etiology (SIRS)/sepsis/fever of unknown origin (FUO), and suspected systemic connective tissue disease.

The diagnosis of HLH was based on the criteria proposed by the HLH Study Group of the Histiocyte Society in 2004 (HLH-2004) and in some cases on Ravelli's criteria [5, 17]. According to the $\mathrm{HLH}-2004$, at least 5 of 8 diagnostic criteria must be fulfilled for HLH diagnosis: (1) fever, (2) splenomegaly, (3) cytopenia affecting $\geq 2$ cell lines (hemoglobin $<90 \mathrm{~g} / \mathrm{l}$, and in infants $<100 \mathrm{~g} /$; ; platelet count $<100 \times 10^{9} /$; n neutrophils $<1.0 \times 10^{9} /$ l), (4) hyperferritinemia (>500 $\mu \mathrm{g} / \mathrm{l}$ ), (5) hypertriglyceridemia (fasting triglycerides $>3.0 \mathrm{mmol} / \mathrm{l}$ ) and/or hypofibrinogenemia (< $1.5 \mathrm{~g} / \mathrm{l})$, (6) hemophagocytosis in bone marrow, spleen, liver, or lymph nodes, (7) elevated level of sIL-2R $\alpha>2400 \mathrm{U} / \mathrm{ml}$, (8) low/absent NK cell activity [5]. Exclusion of primary HLH was performed using functional tests and molecular genetics modalities according to standard practice [1].

The diagnosis of systemic connective tissue diseases was determined at the time of the diagnosis of HLH or during follow-up in the Rheumatology Institute in Warsaw.

Therapies used for SHLH have been evaluated. A frontline therapy of HLH has included high-dose glucocorticoids (GCs-hd) or standard-dose glucocorticoids (GCs-sd) with methylprednisolone (10-30 mg/kg/day or 1-2 mg/kg/day, respectively), with or without addition of IVIG (1-2 g/kg/day) and/or cyclosporine A (CyA) (3-5 mg/kg/day). Additionally, patients with severe $\mathrm{HLH}$ were treated with etoposide (100-150 mg/m²/dose i.v.) or biological response modifiers (infliximab). Some of them required therapy in the intensive care unit (ICU) and hemodiafiltration. The treatment was individualized, depending on the patient's clinical 
condition (if the clinical status of the child was more serious then the therapy was started faster) or currently used routines in the department.

The influence of particular HLH therapy on clinical symptoms - fever, splenomegaly and hepatomegaly (assessed by computed tomography or ultrasound), and laboratory markers of HLH (s-ferritin, s-fibrinogen, and whole blood thrombocytes) - was retrospectively studied.

Response to the therapy was analyzed depending on type of the used treatment and the time point for its introduction in relation to the diagnosis of $\mathrm{HLH}$. According to the above, the patients were divided into the following subgroups:

a) that had received GCS-hd within the first $24 \mathrm{~h}$, b) that had not received GCS-hd within the first $24 \mathrm{~h}$,

c) that had received GCS-hd within the first $72 \mathrm{~h}$,

d) that had not received GCS-hd within the first $72 \mathrm{~h}$,

e) that had received GCS-hd together with IVIG, CsA,

f) that had received GCS-hd together with CSA,

g) where other treatments, but different to GCS-hd, were applied.

Two time points were established, with respect to which the behavior of the measured parameters was monitored. T1 was the third day of the combined action of the interventions applied in the first days from diagnosis. 12 was the seventh day after the last intervention applied during the first $72 \mathrm{~h}$ after diagnosis. If within 7 days of administration of the last intervention in the first $72 \mathrm{~h}$, other interventions were used, T2 was taken as the point after $72 \mathrm{~h}$ of administration of the last intervention during the first 7 days after diagnosis.

\section{Statistical analysis}

The laboratory parameters examined have numeric values - ferritin and fibrinogen concentration and platelet count; clinical parameters were presented as discrete numbers of days after which a given symptom abated after the application of a given intervention (i.e., resolution of fever, hepatomegaly, and splenomegaly).

Percentage values are shown for patients in given groups, range, average, standard deviation for the variable describing the percentages (in the context of the magnitude of changes) by which there was a decrease in the concentration of ferritin, an increase in the concentration of fibrinogen, a decline in the number of platelets, or an abatement of fever, hepatomegaly and splenomegaly these were accepted as endpoints.

It was then evaluated whether the percentage of patients (named as p1) in whom the endpoint had been reached in the period T1-T2 in one of the groups a-f was significantly higher than the percentage of patients (named as p2) in the other groups ((a) vs. (b); (c) vs. (d); (e) vs. (g)). The verification whether 1 was significantly higher than p2 was made on the basis of the methods implemented and available in the package ExactCldiff, environment $R$, depending on the identification of the confidence intervals at the confidence level $(1-\alpha)$ for the difference of percentages $p 1-p 2$. Statistical methods were based on construction of the smallest one-sided confidence interval for the difference between two proportions $[18,19]$.

A positive difference $(\mathrm{p} 1-\mathrm{p} 2>0)$ led to the conclusion that at a significant $\alpha$ level, it can be concluded that $p 1$ was significantly higher than p2. The number of days for fever to abate was considered as a quantitative variable.

On the basis of the Wilcoxon test, it was assessed whether there was a difference in time for the abatement of fever for each pair: (a) vs. (b), (c) vs. (d), (e) vs. (g).

The study protocol was developed according to the ethical standards of the Declaration of Helsin$\mathrm{ki}$ and approved by the institutional ethics committee at the Children's Memorial Health Institute. All patients or legal guardians provided their written informed consent.

\section{Results}

In all 24 studied patients (17 girls and 7 boys), HLH was associated with autoimmune disease, infection or unidentified trigger. The majority of patients $(14 / 24,58 \%)$ suffered from HLH in the course of an autoimmune disease: 12 patients were diagnosed with a systemic form of juvenile idiopathic arthritis (sJ|A), 1 patient had systemic lupus erythematosus, and another 1 had Kawasaki disease. In almost all of them, MAS was the first manifestation of systemic connective tissue diseases (13/14, 93\%). Six patients suffered from a one-time episode of HLH of unknown etiology, and in 4 patients HLH was identified in the course of infection without diagnosis of systemic disease in the annual follow-up. The detailed causes of sHLH in the analyzed group and clinical and biological characteristics are presented in Tables I and II.

The most common therapeutic interventions used were pulses of methylprednisolone $(n=23$, $96 \%$ of patients), CyA $(n=21,88 \%)$, and IVIG $(n=19,79 \%)$. Standard glucocorticoid doses were used in $29 \%$ of patients. Over one third of patients required supportive treatment in the ICU $(n=9$, $38 \%$ ). Rarely ( $n=2,8 \%$ of patients) other interventions were applied (etoposide, infliximab, hemodiafiltration) (Figure 1).

All patients were treated with empirical broad spectrum antibiotics. In the first $72 \mathrm{~h}$ after the diagnosis of $\mathrm{HLH}$, at the same time, or with a small interval, within $72 \mathrm{~h}$, the most common interven- 
Table I. Causes of sHLH/MAS and triggering factors

\begin{tabular}{|c|c|}
\hline Primary disease-inducing agents & Number of patients (\%) \\
\hline MAS (systemic juvenile idiopathic arthritis) & $12(50)$ \\
\hline MAS (Kawasaki disease) & $1(4)$ \\
\hline MAS (systemic lupus erythematosus) & $1(4)$ \\
\hline sHLH/MAS as the first manifestation of autoimmune disease & $13 / 14(93)$ \\
\hline Infection-associated HLH: & $4(17)$ \\
\hline Mycobacterium & $1(4)$ \\
\hline Borrelia & $1(4)$ \\
\hline Parvovirus B19 & $1(4)$ \\
\hline EBV & $1(4)$ \\
\hline HLH of unknown etiology & $6(25)$ \\
\hline Possible infectious trigger of sHLH/MAS: & $17(71)$ \\
\hline EBV & $4(16)$ \\
\hline CMV & $2(8)$ \\
\hline $\begin{array}{l}\text { Others (Mycoplasma, Yersinia, Toxocara, Staphylococcus spp., } \\
\text { Streptococcus spp., Rotavirus) }\end{array}$ & $9(38)$ \\
\hline Etanercept as possible sHLH/MAS trigger & $1(4)$ \\
\hline Unidentified sHLH/MAS triggers & $8(33)$ \\
\hline
\end{tabular}

sHLH/MAS - secondary hemophagocytic lymphohistiocytosis/macrophage activation syndrome, GCs-hd - high-dose glucocorticoids, GCs-sd - standard-dose glucocorticoids, CyA - cyclosporine A, IVIG - intravenous immunoglobulins, ICU - intensive care unit, EBV - EpsteinBarr virus, CMV - cytomegalovirus.

tions were associated with treatment with pulses of methylprednisolone, IVIG and CyA $(n=7,29 \%)$ and pulses of GCs together with CyA $(n=5,20 \%$ of patients). Twelve (50\%) patients received a pulse of GCs in the first $24 \mathrm{~h}$ after diagnosis, 17 (71\%) during the first $72 \mathrm{~h}$. Seven patients (29\%) did not receive a pulse of GCs in the first $72 \mathrm{~h}$.

Patients required therapy in the ICU on average after $72 \mathrm{~h}$ from the diagnosis of $\mathrm{HLH}$, the earliest within the first $48 \mathrm{~h}, 50 \%$ on the second or third day after diagnosis of $\mathrm{HLH}$, the remainder $50 \%$ later, but not later than on the seventh day after diagnosis.

All of the patients ( $n=24,100 \%)$ were alive, during the early and late follow-up (1 to 8 years). There were no infectious complications when steroid therapy was used, long-term complications, or recurrence of $\mathrm{HLH} ; 14$ patients remain under rheumatologic care, 12 of them diagnosed with SJIA; in 8 patients transient symptoms of iatrogenic Cushing's syndrome were observed.

Time point T1 most often was found on the third or fourth day after diagnosis, point T2 on the seventh to ninth day. A detailed presentation of time points for each patient, the type of intervention, and laboratory and clinical parameters values are presented in Tables III and IV. In Table V we present the percentages of patients and basic statistical data for the variables describing the endpoints and in Tables VI and VII the confidence intervals for the difference of patients with improvement of the parameter for each of the three pairs of groups.

It was found, with a confidence level of $90 \%$, that the percentage of patients with an increase in the number of thrombocytes and fibrinogen among those patients who received the pulses of GCs in the first $24 \mathrm{~h} \mathrm{(a)} \mathrm{with} \mathrm{respect} \mathrm{to} \mathrm{those} \mathrm{who} \mathrm{at} \mathrm{that}$ time did not receive it (b) is significantly greater.

In the case of a decrease in the concentration of ferritin, with a confidence level of at least $90 \%$, we have no reason to conclude that there was a significant difference in the percentage of patients with decreasing ferritin in groups (a) vs. (b); however, it is observed that the maximum difference applies to patients from (e) and (g).

When comparing the groups of patients who were given (c) and who were not given (d) GCs-hd in the first 3 days, there are no significant percentage differences, while in the case of groups of patients who were given GCs-hd with IVIG, CyA (e) and patients who were given other, but different from the GCs-hd interventions (g), with $90 \%$ confidence, it can be concluded that the application for the first 3 days of the pulse of GCs with IVIG and CyA significantly increases the chances of an increase in fibrinogen compared to patients who did not receive the pulse of GCs in the first 3 days. 
Table II. Characteristics of patients

\begin{tabular}{|c|c|c|c|c|}
\hline Patients & $\begin{array}{c}\text { Age } \\
\text { [years] }\end{array}$ & sHLH subtype & Possible trigger & Clinical symptoms \\
\hline 1 & 11 & PV-B19-HLH & PV-B19 & $\begin{array}{c}\text { Fever, hepatosplenomegaly, subcutaneous edema, } \\
\text { erythema, interstitial pneumonitis, serositis, } \\
\text { microhematuria }\end{array}$ \\
\hline 2 & 2 & so-JIA-HLH & Unknown & Fever, hepatosplenomegaly, arthritis, rash \\
\hline 3 & 11 & so-JIA-HLH & EBV & $\begin{array}{l}\text { Fever, hepatosplenomegaly, lymphadenopathy, rash, } \\
\text { arthritis, seizures, multi-organ dysfunction }\end{array}$ \\
\hline 4 & 5 & UE-HLH & Unknown & $\begin{array}{l}\text { Fever, hepatosplenomegaly, rash, pericarditis, } \\
\text { palmar erythema }\end{array}$ \\
\hline 5 & 10 & UE-HLH & Unknown & $\begin{array}{l}\text { Fever, hepatosplenomegaly, rash, serositis, } \\
\text { pneumonitis, respiratory failure }\end{array}$ \\
\hline 6 & 6 & so-JIA-HLH & RV & $\begin{array}{c}\text { Fever, hepatosplenomegaly, hemorrhagic rash, } \\
\text { diarrhea }\end{array}$ \\
\hline 7 & 6 & UE-HLH & Unknown & Fever, hepatosplenomegaly, arthritis, bradycardia \\
\hline 8 & 14 & so-JIA-HLH & $\begin{array}{l}\text { Streptococcus } \\
\quad \text { viridans }\end{array}$ & $\begin{array}{l}\text { Fever, hepatosplenomegaly, subcutaneous edema, } \\
\text { aphthous stomatitis, arthritis, seizures, brain edema, } \\
\text { interstitial pneumonitis }\end{array}$ \\
\hline 9 & 1 & UE-HLH & Unknown & $\begin{array}{l}\text { Fever, hepatosplenomegaly, livedo reticularis, rash, } \\
\text { renal failure }\end{array}$ \\
\hline 10 & 9 & EBV-HLH & EBV & $\begin{array}{l}\text { Fever, hepatosplenomegaly, hemorrhagic rash, } \\
\text { lymphadenopathy, serositis, arthritis }\end{array}$ \\
\hline 11 & 7 & so-JIA-HLH & EBV & $\begin{array}{l}\text { Fever, splenomegaly, arthritis, pneumonia, } \\
\text { generalized rash, palmar abscess }\end{array}$ \\
\hline 12 & 15 & SLE-HLH & $\begin{array}{l}\text { Mycobacterium } \\
\text { tuberculosis }\end{array}$ & $\begin{array}{l}\text { Fever, hepatosplenomegaly, lymphadenopathy, malar } \\
\text { rash, proteinuria, serositis }\end{array}$ \\
\hline 13 & 12 & Borrelia-HLH & Borrelia burgdorferi & Fever, hepatosplenomegaly, headache \\
\hline 14 & 9 & so-JIA-HLH & Mycoplasma & Fever, splenomegaly, arthritis, rash, lymphadenopathy \\
\hline 15 & 10 & so-JIA-HLH & Yersinia & $\begin{array}{l}\text { Fever, hepatosplenomegaly, abdominal } \\
\text { lymphadenopathy, generalized rash }\end{array}$ \\
\hline 16 & 17 & $\begin{array}{l}\text { Mycobacterium- } \\
\text { HLH }\end{array}$ & $\begin{array}{c}\text { Mycobacterium } \\
\text { xenopi }\end{array}$ & $\begin{array}{c}\text { Fever, hepatomegaly, peripheral edema, arrhythmia, } \\
\text { interstitial pneumonitis, heart and respiratory failure, } \\
\text { cholecystitis }\end{array}$ \\
\hline 17 & 8 & So-JIA-HLH & CMV & $\begin{array}{l}\text { Fever, hepatosplenomegaly, generalized erythema, } \\
\text { lymphadenopathy, polyneuropathy, haemoptysis, } \\
\text { multi-organ dysfunction }\end{array}$ \\
\hline 18 & 2 & so-JIA-HLH & $\begin{array}{l}\text { Staphylococcus } \\
\text { epidermidis }\end{array}$ & $\begin{array}{l}\text { Fever, hepatosplenomegaly, lymphadenopathy, } \\
\text { serositis, conjunctivitis }\end{array}$ \\
\hline 19 & 16 & so-JIA-HLH & CMV & Fever, hepatosplenomegaly, rash, myositis, serositis \\
\hline 20 & 6 & So-JIA-HLH & Etanercept & $\begin{array}{l}\text { Fever, arthritis, stomatitis, post reversible } \\
\text { encephalopathy syndrome }\end{array}$ \\
\hline 21 & 14 & UE-HLH & Unknown & Fever, rash, lymphadenopathy, pneumonitis \\
\hline 22 & 6 & UE-HLH & EBV & $\begin{array}{l}\text { Fever, hepatosplenomegaly, lymphadenopathy, } \\
\text { pneumonitis, pleuritis, seizures, encephalitis }\end{array}$ \\
\hline 23 & 2 & KD-HLH & Unknown & $\begin{array}{c}\text { Fever, hepatosplenomegaly, lymphadenopathy, } \\
\text { peripheral edema, palmar erythema, conjunctivitis, } \\
\text { red, cracked lips }\end{array}$ \\
\hline 24 & 3 & So-JIA-HLH & Unknown & $\begin{array}{l}\text { Fever, splenomegaly, lymphadenopathy, interstitial } \\
\text { pneumonitis, conjunctivitis, arthritis }\end{array}$ \\
\hline
\end{tabular}

With a confidence level of $95 \%$, it can be concluded that administration of GCs-hd on the first day or in the first three days from sHLH/MAS diag- nosis has a favorable effect on the rapid resolution of fever and hepatomegaly. With respect to splenomegaly, this confidence can be placed at the 
level of $90 \%$. Additionally, in the case of patients who had a pulse of GCs in the first 3 days (c) with respect to those who did not have this intervention at that time $(d)$, this conclusion may be given at a higher level of confidence of $95 \%$.

\section{Discussion}

There are no exact data on the incidence of any form of acquired HLH. Our approximately 9-year-long observation suggests that the majority of children (58\%) hospitalized for severe $\mathrm{SHLH} /$ MAS may suffer from autoimmune disease (both known and unknown at the time of sHLH/MAS diagnosis).

The choice of initial HLH treatment is difficult for several reasons. Some authors stress the need for aggressive treatment of HLH at the diagnosis, because the initial period of this syndrome is burdened with multi-organ complications and higher mortality [20-22]. Moreover, selection of optimal therapeutic interventions is difficult due to the inability to determine the cause of HLH and exclude genetically conditioned states (diagnostic and methodical limitations) in the early days of the disease. Secondary HLH is most often characterized by such features as age $>2$ years, symptoms characteristic of systemic diseases, malignancies, circulatory failure symptoms, elevated levels of CRP, procalcitonin, CD163, increased number of leukocytes with a left shift, ferritin concentration $>10,000$, no signs of acute liver failure, changes in the central nervous system, and hypogammaglobulinemia [23-28].

In the case of MAS, Ravelli et al. offered separate criteria for children with SJIA; however, in clinical practice, the HLH-2004 criteria proposed by the Histiocyte Society are commonly accepted $[24,29,30]$. In a recent paper, Davi et al. reported that HLH-2004 guidelines are likely not appropriate for identification of MAS in children with SIIA, because preliminary MAS guidelines showed the strongest ability to identify MAS in SJIA [31]. Currently, efforts are being made to establish the criteria for other forms of MAS, among others those based on the international consensus from 2011 [15]. The immunochemotherapy protocol proposed by the HLH Study Group is intended primarily for genetically conditioned states, and the authors point out that the treatment of SHLH should be targeted at treatment of the underlying condition [5]. However, when necessary (e.g., patients with recurrent or treatment-resistant $\mathrm{HLH}$ ) the HLH-2004 protocol should be applied. In the case of a clinical suspicion of $\mathrm{HLH}$, it is acceptable to start treatment before the patient meets the HLH-2004 criteria for diagnosis [5]. The results presented in this study confirm the belief, widely accepted in clinical practice (especially rheumato-

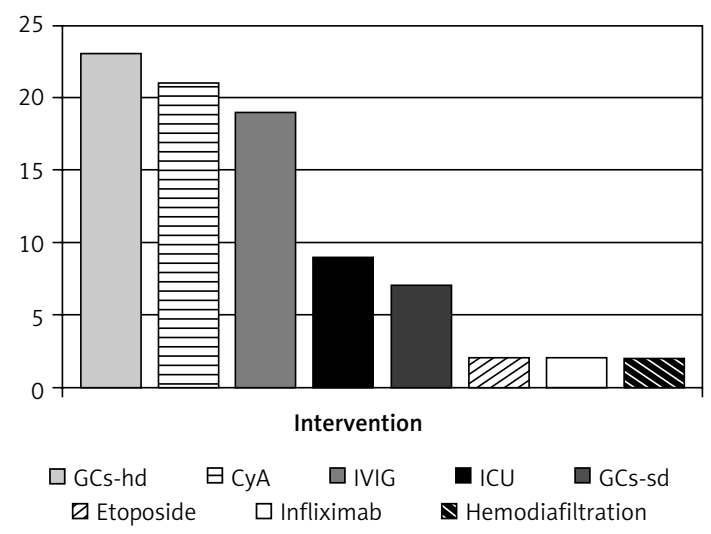

Figure 1. Administration frequency of different interventions in the studied SHLH/MAS patients

SHLH/MAS - secondary hemophagocytic lymphohistiocytosis/macrophage activation syndrome, GCs-hd - high-dose glucocorticoids, GCs-sd - standard-dose glucocorticoids, CyA - cyclosporine A, IVIG - intravenous immunoglobulins, ICU - intensive care unit.

logical), that patients with SHLH/MAS usually do not require the use of chemotherapy; in immunosuppression treatment, the main role is played by glucocorticoids and CyA [24, 30, 32, 33]. There are no conduct guidelines that relate to the doses of drugs and indications to extend treatment. Commonly applied treatment is based on the opinions of experts, case descriptions, and the personal experiences of given centers; it remains a matter that is often controversial. It is believed that minimal immunosuppression should be applied, which, on one hand, will control inflammation, and, on the other, minimize the risk of infectious complications during treatment, which constitute one of the main causes of death among patients with $\mathrm{HLH}$. High doses of GCs are recommended by most authors as a first line of treatment; according to others, the first-line treatment is CyA [12, 14, 25, 32, 34-37]. Still others emphasize the crucial importance of IVIG, especially in the initial phase of treatment, increasing the concentration of ferritin [36]. Combined therapies are also common, for which indications are determined in each case individually.

The inflammatory cytokines are considered to play a key role in the pathogenesis of MAS. Successful treatment of severe pediatric rheumatic disease-associated MAS with interleukin-1 inhibition (anakinra) following conventional immunosuppressive therapy has been recently observed in a case series study [38]. Tumor necrosis factor (TNF) is considered a major proinflammatory cytokine, affecting various aspects of the immune reaction [39]. TNF- $\alpha$ inhibitors have demonstrated efficacy in patients with MAS who were refractory to conventional therapy [40]. In our study, infliximab was administered with good clinical response. However, it must be mentioned that 


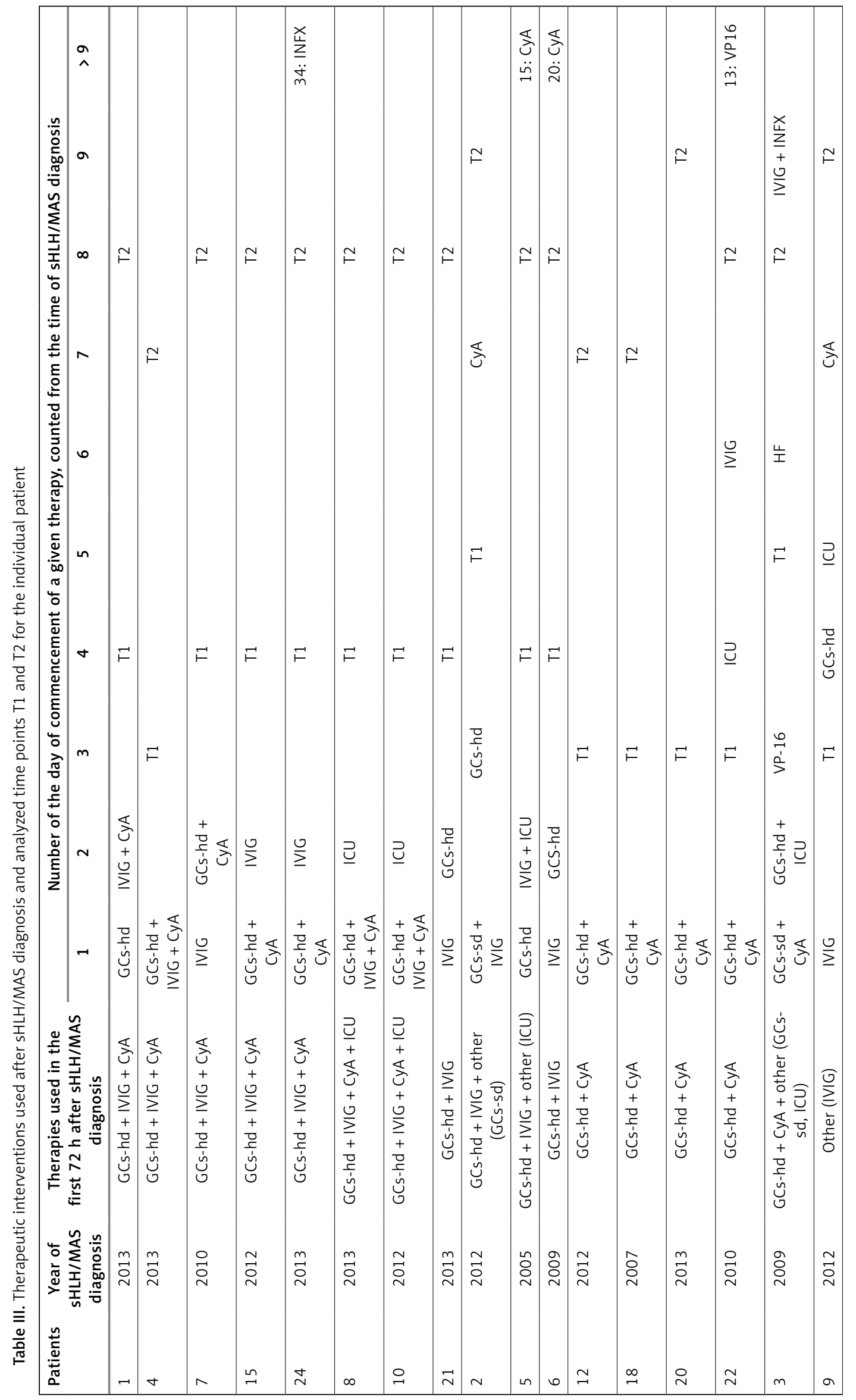




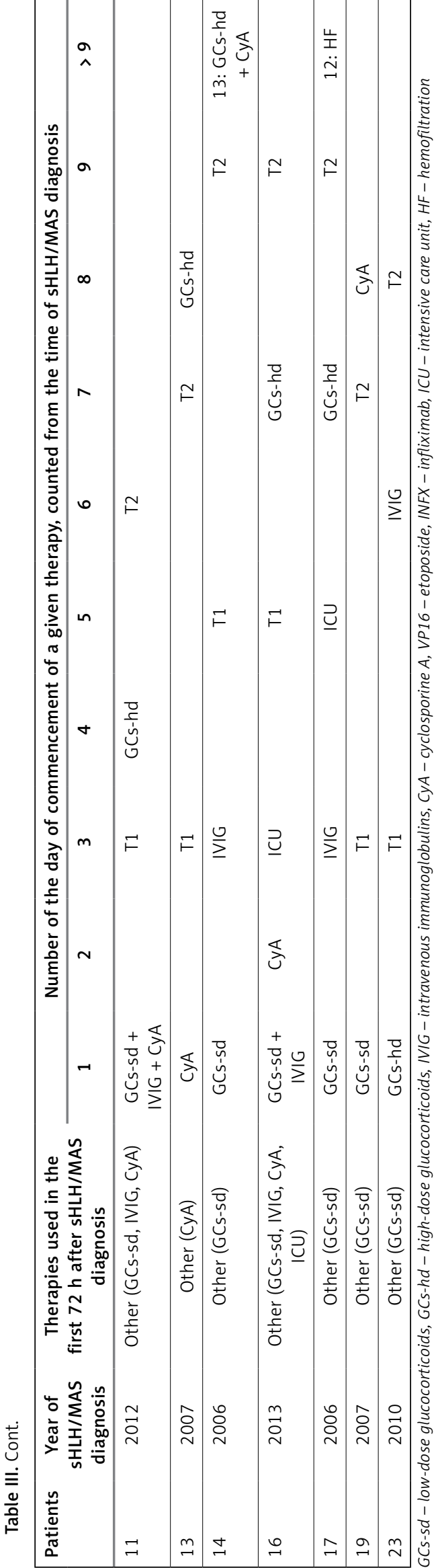

patients on TNF- $\alpha$ inhibitors (infliximab, adalimumab, etanercept) are at higher risk of infections, e.g. reactivation of latent tuberculosis [41]. Other potential side effects, including malignancies, have also been observed after therapy with TNF- $\alpha$ inhibitors. Nevertheless, there are conflicting data on this issue without convincing evidence for increased risk of lymphoma or solid tumors solely due to the anti-TNF therapy [39, 42]. Moreover, some case reports have postulated the development of MAS after initiation of TNF- $\alpha$ inhibitors in patients with rheumatic diseases as a possible result of the cytokine dysregulation [43]. However, there is no reliable evidence supporting this hypothesis, since it could be the natural course of the disease and a coincidence with onset of the therapy. Further prospective studies on this approach are required to better define the role of biological agents in the management of MAS.

In the present study, the basic methodology was a combined treatment: pulses of methylprednisolone \pm IVIG +/and CyA, although the selection of optimal therapy was in each case individualized. The delay in implementation of GCs in some children was usually associated with the need to carry out diagnostics, which would be difficult after administration of GCs (histopathological examination of bone marrow and tissue). In cases of a severe, life-threatening condition, GC treatment was started at the time of diagnosis. Simultaneously, all the children had anti-bacterial and anti-fungal treatment (empirical), focused on the potential cause of $\mathrm{HLH}$, as well as prevention of infections. We did not observe secondary infection as an iatrogenic complication of the treatment.

All of the patients survived; hence in this study we examined selected clinical parameters that, according to the work of other authors, are clinically important prognostic factors (endpoints) for patients with HLH (i.e., fever, splenomegaly, concentrations of ferritin, fibrinogen, bilirubin, albumin, hemoglobin, and thrombocytes) [44-47].

In the present study over one third of patients required supportive treatment in the ICU (38\%). These results are similar to others recently reported [48]. The reason for treatment in intensive care in all cases was worsening of cardiopulmonary insufficiency, which was probably related to involvement of heart muscle (inflammation of the pericardium and/or myocardium) or lungs (interstitial infiltrates). We believe that the improvement or deterioration in the analyzed laboratory parameters was not related directly to cardiopulmonary and respiratory failure or hospitalization in the ICU.

The results we report support the benefits of combined sHLH/MAS therapy and early implementation of GCs in high doses - faster resolution of fever, hepatosplenomegaly, and the rise of 


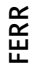

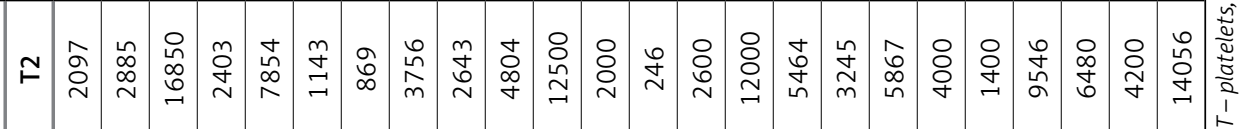

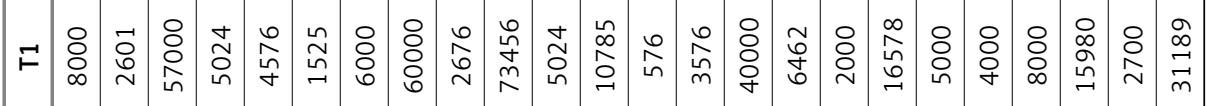

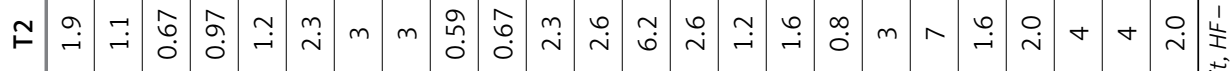

巡

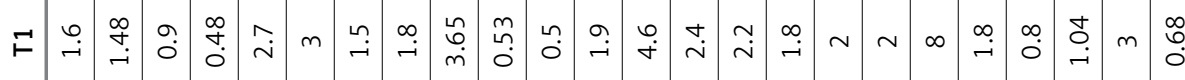

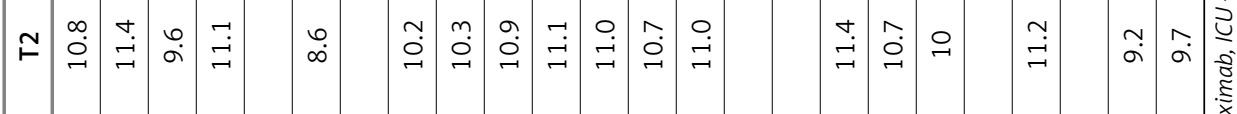

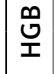

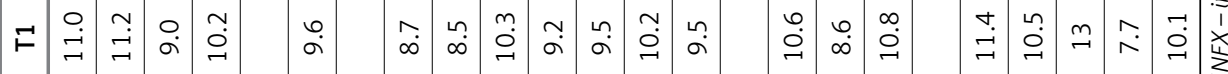

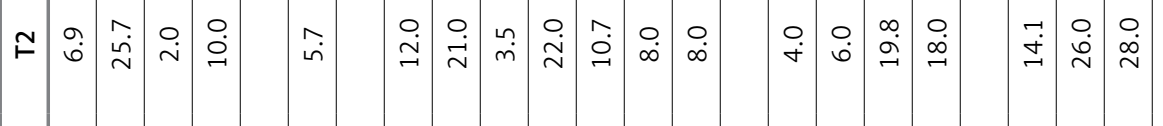

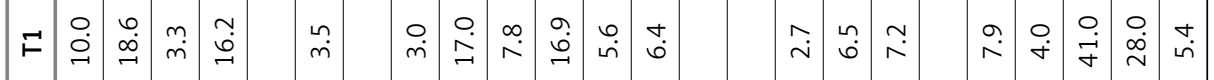

F

๖

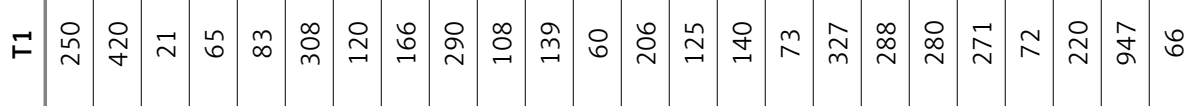


Table V. Comparison of behavior of HLH parameters (ferritin, platelets, fibrinogen, duration of fever, hepatomegaly and splenomegaly) with three established divisions of test groups

\begin{tabular}{|c|c|c|c|c|c|c|c|}
\hline & \multicolumn{2}{|c|}{$\begin{array}{l}\text { GCs-hd intervention in } \\
\text { the first } 24 \mathrm{~h} \text { after sHLH/ } \\
\text { MAS diagnosis }\end{array}$} & \multicolumn{2}{|c|}{$\begin{array}{l}\text { GCs-hd intervention in } \\
\text { the first } 72 \mathrm{~h} \text { after sHLH/ } \\
\text { MAS diagnosis }\end{array}$} & \multicolumn{3}{|c|}{$\begin{array}{l}\text { Intervention in the first } 72 \mathrm{~h} \text { after } \\
\text { sHLH/MAS diagnosis }\end{array}$} \\
\hline & $\begin{array}{c}\text { Yes } \\
(n=12, \\
100 \%) \\
(a)\end{array}$ & $\begin{array}{c}\text { No } \\
(n=12, \\
100 \%) \\
\text { (b) }\end{array}$ & $\begin{array}{c}\text { Yes } \\
(n=17, \\
100 \%) \\
(c)\end{array}$ & $\begin{array}{c}\text { No } \\
(n=7,100 \%) \\
\text { (d) }\end{array}$ & $\begin{array}{c}\text { GCs-hd } \\
\text { IVIG } \\
\text { CyA } \\
(n=7,100 \%) \\
\text { (e) }\end{array}$ & $\begin{array}{c}\text { GCs-hd } \\
\text { CyA } \\
(n=5,100 \%) \\
\text { (f) }\end{array}$ & $\begin{array}{l}\text { Others, but } \\
\text { different to } \\
\text { GCs-hd } \\
\text { (n=7,100\%) } \\
\text { (g) }\end{array}$ \\
\hline \multicolumn{8}{|c|}{ Decrease of ferritin: } \\
\hline$\%$ persons & 83.3 & 66.7 & 76.5 & 71.4 & 100 & 100 & 62.5 \\
\hline Min-max ${ }^{1}$ & $52.2-93.7$ & $1.2-85.5$ & $25.0-93.7$ & $1.2-57.3$ & $52.2-93.7$ & $59.4-81.5$ & $1.2-57.3$ \\
\hline Mean \pm SD & $70.9 \pm 14.8$ & $37.8 \pm 29.6$ & $68.4 \pm 18.7$ & $24.2 \pm 20.8$ & $74.8 \pm 17.1$ & $68.2 \pm 8.4$ & $24.2 \pm 20.8$ \\
\hline Median & 67.5 & 26.1 & 70.0 & 20.0 & 73.8 & 65.0 & 20.0 \\
\hline \multicolumn{8}{|c|}{ Increased platelet count: } \\
\hline$\%$ persons & 91.7 & 66.7 & 82.4 & 71.4 & 100 & 80 & 75 \\
\hline Min-max & $29.2-434.9$ & $7.1-419.4$ & $29.2-434.9$ & $7.1-124.3$ & $80.7-346.2$ & $29.2-375.0$ & $7.1-419.4$ \\
\hline Mean \pm SD & $185.8 \pm 135.68$ & $134.7 \pm 129.4$ & $195.7 \pm 139.2$ & $76.4 \pm 48.0$ & $164.9 \pm 90.2$ & $165.8 \pm 151.7$ & $133.6 \pm 146.5$ \\
\hline Median & 127.3 & 97.4 & 145.8 & 77.0 & 127.3 & 127.3 & 97.4 \\
\hline \multicolumn{8}{|c|}{ Increase in fibrinogen: } \\
\hline$\%$ persons & 75.0 & 41.7 & 64.7 & 42.9 & 85.7 & 60.0 & 50.0 \\
\hline Min-max & $18.7-284.6$ & $8.3-360.0$ & $18.7-284.6$ & $8.3-360.0$ & 18.7-194.1 & $36.8-284.6$ & $8.3-360.0$ \\
\hline Mean $\pm S D$ & $90.3 \pm 90.9$ & $130.6 \pm 139.7$ & $96.6 \pm 83.3$ & $134.4 \pm 195.8$ & $84.7 \pm 64.2$ & $123.8 \pm 139.4$ & $138.3 \pm 160.1$ \\
\hline Median & 50.0 & 100.0 & 66.7 & 34.8 & 83.3 & 50.0 & 92.4 \\
\hline \multicolumn{8}{|c|}{ Number of days to abatement of fever: } \\
\hline Min-max & $0-8$ & $1-15$ & $0-8$ & $1-15$ & $1-2$ & $0-1$ & $1-15$ \\
\hline Mean \pm SD & $1.7 \pm 2.1$ & $4.2 \pm 4.3$ & $1.6 \pm 1.8$ & $6.1 \pm 4.8$ & $1.1 \pm 0.4$ & $0.8 \pm 0.5$ & $5.6 \pm 4.7$ \\
\hline Median & 1 & 2 & 1 & 7 & 1 & 1 & 5 \\
\hline \multicolumn{8}{|c|}{ Percentage of cases with a given number of days to abatement of hepatomegaly: } \\
\hline 0 & 8.3 & 16.7 & 11.8 & 14.3 & 0 & 20.0 & 25.0 \\
\hline $1-7$ & 33.3 & 16.7 & 35.3 & 0 & 42.9 & 0 & 0 \\
\hline $8-14$ & 50.0 & 8.3 & 41.2 & 0 & 57.1 & 60.0 & 0 \\
\hline$>14$ & 8.3 & 58.3 & 11.8 & 85.7 & 0 & 20.0 & 75.0 \\
\hline \multicolumn{8}{|c|}{ Percentage of cases with a given number of days to abatement of splenomegaly: } \\
\hline 0 & 25.0 & 25.0 & 29.4 & 14.3 & 14.3 & 40.0 & 25.0 \\
\hline $1-7$ & 66.7 & 41.7 & 64.7 & 28.6 & 71.4 & 60.0 & 25.0 \\
\hline $8-14$ & 8.3 & 25.0 & 5.9 & 42.9 & 14.3 & 0 & 37.5 \\
\hline$>14$ & 0 & 8.3 & 0 & 14.3 & 0 & 0 & 12.5 \\
\hline
\end{tabular}

$n$ - number, SD - standard deviation, Min - minimum value, Max - maximum value, sHLH/MAS - secondary hemophagocytic lymphohistiocytosis/macrophage activation syndrome, GCs-hd - high-dose glucocorticoids, IVIG - intravenous immunoglobulins, CyA cyclosporine A.

${ }^{1}$ Range, average, SD and median for the variable describing how far, as a percentage, the value of ferritin decreased between T1 and T2, similarly for the other two growth parameters 
Table VI. Division of confidence levels into levels of confidence of $95 \%$ and $90 \%$ for the difference of patients, respectively, with the decline of ferritin, and increase in thrombocytes and fibrinogen

\begin{tabular}{|lccc|}
\hline & (a) vs. (b) & (c) vs. (d) & (e) vs. (g) \\
\hline Decrease of ferritin & {$[-0.14 ; 1.00]$} & {$[-0.26 ; 1.00]$} & {$[-0.09 ; 1.00]$} \\
& {$[-0.10 ; 1.00]$} & {$[-0.21 ; 1.00]$} & {$[-0.003 ; 1.00]$} \\
\hline Increase in thrombocytes & {$[-0.04 ; 1.00]$} & {$[-0.19 ; 1.00]$} & {$[-0.09 ; 1.00]$} \\
& {$[0.02 ; 1.00]$} & {$[-0.13 ; 1.00]$} & {$[-0.003 ; 1.00]$} \\
\hline Increase in fibrinogen & {$[-0.04 ; 1.00]$} & {$[-0.17 ; 1.00]$} & {$[-0.08 ; 1.00]$} \\
& {$[0.03 ; 1.00]$} & {$[-0.08 ; 1.00]$} & {$[0.02 ; 1.00]$} \\
\hline
\end{tabular}

a) high-dose glucocorticoids administered $\leq 24 \mathrm{~h}$ after diagnosis of hemophagocytic lymphohistiocytosis (HLH), b) high-dose glucocorticoids administered $>24 \mathrm{~h}$ after diagnosis of $\mathrm{HLH}, \mathrm{c}$ ) high-dose glucocorticoids administered $\leq 72 \mathrm{~h}$ after diagnosis of $\mathrm{HLH}$, d) high-dose glucocorticoids administered $>72 \mathrm{~h}$ after diagnosis of $\mathrm{HLH}$, e) high-dose glucocorticoids administered together with intravenous immunoglobulins and cyclosporine A, f) high-dose glucocorticoids administered together with cyclosporine A, g) therapy other than high-dose glucocorticoids.

Table VII. Division of confidence levels into levels of confidence of $95 \%$ and $90 \%$ for the difference of patients, respectively, for a time of abatement of hepatomegaly > 14 days and for a time of abatement of splenomegaly $>14$ days

\begin{tabular}{|lccc|}
\hline & $(\mathrm{a})$ vs. $(\mathrm{b})$ & (c) vs. $(\mathrm{d})$ & $(\mathrm{e})$ vs. $(\mathrm{g})$ \\
\hline Hepatomegaly $>14$ days & {$[-1.00 ;-0.18]$} & {$[-1.00 ;-0.36]$} & {$[-1.00 ;-0.41]$} \\
& {$[-1.00 ;-0.24]$} & {$[-1.00 ;-0.44]$} & {$[-1.00 ;-0.49]$} \\
\hline Splenomegaly $>14$ days & {$[-1.00 ; 0.04]$} & {$[-1.00 ;-0.16]$} & {$[-1.00 ; 0.22]$} \\
& {$[-1.00 ;-0.02]$} & {$[-1.00 ;-0.22]$} & {$[-1.00 ;-0.02]$} \\
\hline
\end{tabular}

a) high-dose glucocorticoids administered $\leq 24 \mathrm{~h}$ after diagnosis of hemophagocytic lymphohistiocytosis (HLH), b) high-dose glucocorticoids administered > $24 \mathrm{~h}$ after diagnosis of $\mathrm{HLH}, \mathrm{c}$ ) high-dose glucocorticoids administered $\leq 72 \mathrm{~h}$ after diagnosis of $\mathrm{HLH}$, d) high-dose glucocorticoids administered $>72 \mathrm{~h}$ after diagnosis of $\mathrm{HLH}, \mathrm{e}$ ) high-dose glucocorticoids administered together with intravenous immunoglobulins and cyclosporine A, f) high-dose glucocorticoids administered together with cyclosporine A, g) therapy other than highdose glucocorticoids.

fibrinogen concentration and platelet count. No statistically significant differences were found for the combination of associated therapies with respect to the concentration of ferritin.

We are aware that the study has certain limitations. It is a retrospective population-based analysis from a single center, the group of patients was heterogeneous, and analyzed parameters represent substitute points. We used statistical methods based on construction of the smallest one-sided confidence interval for the difference of two proportions - a method with limited statistical power. Due to the number of comparisons, statistical differences may have been observed by chance. The study was not randomized and the therapy was not standardized. Since the treatment must start from the early beginning of the disease, implementation of a standardized scheme is always very difficult and raises ethical doubts. The treatment was individualized, depending on the patient's clinical condition. Determination of the impact of a given intervention on the clinical course and laboratory test results was one of the aims of the study. Furthermore, several other factors not analyzed in this study can influence the course of $\mathrm{HLH}$. Of significance may be the dosage of drugs used (range of the pulse dose: $10-30 \mathrm{mg} / \mathrm{kg} /$ day), individual metabolism of the drugs (oxygen saturation time, therapeutic dose), interactions between them, and innate immune mechanisms. Finally, the effect evaluated after seven days from the last intervention applied in the first $72 \mathrm{~h}$ from diagnosis is the sum of the effects, which may also be influenced by interventions not included in the analysis, i.e., antibiotic therapy, blood preparations, nutritional or symptomatic therapy.

However, we are unaware of any studies that answer the question what is the influence of particular HLH therapy on clinical symptoms and laboratory markers. We believe that inappropriate treatment such as immunosuppression monotherapy and a delay in the start of treatment may be one of the main unfavorable prognostic factors in patients with $\mathrm{HLH}$. Our main goal was to underline the positive effect of combined immunosuppression as the initial therapy for patients with sHLH.

Further analysis is required. A well-designed, prospective cohort study would provide the strongest scientific evidence.

In conclusion, in the treatment of sHLH/MAS administration of high-dose glucocorticoids, CyA, and IVIG is crucial for a successful outcome. Usually, there is no need for additional chemotherapy. The application of high-dose GCs in the first $24 \mathrm{~h}$ or high-dose GCs in combination with CyA and IVIG in the first $72 \mathrm{~h}$ after diagnosis have a positive influence on the improvement in terms of disease markers such as thrombocytes, fibrinogen concen- 
tration and the alleviation of fever, splenomegaly and hepatomegaly in children with SHLH/MAS.

In recent years, it has been stressed that $\mathrm{SHLH} /$ MAS is a polygenic condition [19, 24]. The clinical course and prognosis may therefore depend not only on intervention but also on the efficiency of the immune mechanisms involved in the pathogenesis of $\mathrm{HLH}$. Further research is essential, aimed at identifying these pathomechanisms, expanding diagnostic methods in patients with $\mathrm{HLH}$ by detailed genetic and functional studies, as they can allow for a more accurate understanding of the essence of HLH and carrying out studies evaluating the impact of commonly used therapeutic interventions ("classic" drugs and immunosuppressive methods vs. chemotherapy) on the clinical course and the choice of optimal treatment.

\section{Conflict of interest}

The authors declare no conflict of interest.

\section{References}

1. Malinowska I, Machaczka M, Popko K, Siwicka A, Salamonowicz M, Nasiłowska-Adamska B. Hemophagocytic syndrome in children and adults. Arch Immunol Ther Exp (Warsz) 2014; 62: 385-94.

2. Weaver LK, Behrens EM. Hyperinflammation, rather than hemophagocytosis, is the common link between macrophage activation syndrome and hemophagocytic lymphohistiocytosis. Curr Opin Rheumatol 2014; 26: 562-9.

3. Henter JI, Elinder G, Söder O, Hansson M, Andersson B, Andersson U. Hypercytokinemia in familial hemophagocytic lymphohistiocytosis. Blood 1991; 78: 2918-22.

4. Chiang SC, Theorell J, Entesarian M, et al. Comparison of primary human cytotoxic T-cell and natural killer cell responses reveal similar molecular requirements for lytic granule exocytosis but differences in cytokine production. Blood 2013; 121: 1345-56.

5. Henter JI, Horne A, Arico M, et al. HLH-2004: Diagnostic and therapeutic guidelines for hemophagocytic lymphohistiocytosis. Pediatr Blood Cancer 2007; 48: 124-31.

6. Rouphael NG, Talati NJ, Vaughan C, Cunningham K, Moreira R, Gould C. Infections associated with haemophagocytic syndrome. Lancet Infect Dis 2007; 7: 814-22.

7. Machaczka M, Vaktnäs J, Klimkowska M, Hägglund H. Malignancy-associated hemophagocytic lymphohistiocytosis in adults: a retrospective population-based analysis from a single center. Leuk Lymphoma 2011; 52: 613-9.

8. Filipovich AH. The expanding spectrum of hemophagocytic lymphohistiocytosis. Curr Opin Allergy Clin Immunol 2011;11:512-6.

9. Grom A, Villanueva J, Lee S, Goldmuntz E, Passo M, Filipovich A. Natural killer cell dysfunction in patients with systemic-onset juvenile rheumatoid arthritis and macrophage activation syndrome. J Pediatr 2003; 142: 292-6.

10. Zhang M, Behrens EM, Atkinson TP, et al. Genetic defects in cytolysis in macrophage activation syndrome. Curr Rheumatol Rep 2014; 16: 439.
11. Canna SW, Behrens EM. Not all hemophagocytes are created equally: appreciating the heterogeneity of the hemophagocytic syndromes. Curr Opin Rheumatol 2012; 24: 113-8.

12. Gupta S, Weitzman S. Primary and secondary hemophagocytic lymphohistiocytosis: clinical features, pathogenesis and therapy. Expert Rev Clin Immunol 2010; 6: 137-54.

13. Janka G. Hemophagocytic lymphohistiocytosis: when the immune system runs amok. Klin Padiatr 2009; 221: 278-85.

14. Machaczka M, Sydor W, Rucińska M, Szostek M, Musiał J. Autoimmune-associated hemophagocytic syndrome/ macrophage activation syndrome. In: Autoimmune disorders - current concepts and advances from bedside to mechanistic insights. Huang FP (ed.). InTech, Rijeka 2011; 79-104.

15. Davi S, Consolaro A, Guseinova D, et al. An international consensus survey of diagnostic criteria for macrophage activation syndrome in systemic juvenile idiopathic arthritis. J Rheumatol 2011; 38: 764-8.

16. Deane S, Selmi C, Teuber SS, Gershwin ME. Macrophage activation syndrome in autoimmune disease. Int Arch Allergy Immunol 2010; 153: 109-20.

17. Ravelli A, Magni-Manzoni S, Pistorio A, et al. Preliminary diagnostic guidelines for macrophage activation syndrome complicating systemic juvenile idiopathic arthritis. J Pediatr 2005; 146: 598-604.

18. Wang W. On construction of the smallest one-sided confidence interval for the difference of two proportions. Ann Stat 2010; 38: 1227-43.

19. Shan G, Wang W. ExactCldiff: an R package for computing exact confidence intervals for the difference of two proportions. R J 2013; 5: 62-70.

20. Sawhney S, Woo P, Murray KJ. Macrophage activation syndrome: a potentially fatal complication of rheumatic disorders. Arch Dis Child 2001; 85: 421-6.

21. Janka GE. Hemophagocytic syndromes. Blood Rev Sep 2007; 21: 245-53.

22. Jordan MB, Allen CE, Weitzman S, Filipovich $A H$, Mc-Clain KL. How I treat haemophagocytic lymphohistiocytosis. Blood 2011; 118: 4041-52.

23. Usmani GN, Woda BA, Newburger PE. Advances in understanding the pathogenesis of $\mathrm{HLH}$. Br J Haematol 2013; 161: 609-22.

24. Mehta RS, Smith RE. Hemophagocytic lymphohistiocytosis (HLH): a review of literature. Med Oncol 2013; 30: 740.

25. Lehmberg K, Ehl S. Diagnostic evaluation of patients with suspected haemophagocytic lymphohistiocytosis. Br J Haematol 2013; 160: 275-87.

26. Lehmberg K, Pink I, Eulenburg C, Beutel K, Maul-Pavicic A, Janka G. Differentiating macrophage activation syndrome in systemic juvenile idiopathic arthritis from other forms of hemophagocytic lymphohistiocytosis. J Pediatr 2013; 162: 1245-51.

27. Strippoli R, Caiello I, De Benedetti F. Reaching the threshold: a multilayer pathogenesis of macrophage activation syndrome. J Rheumatol 2013; 40: 761-7.

28. Faitelson Y, Grunebaum E. Hemophagocytic lymphohistiocytosis and primary immune deficiency disorders. Clin Immunol 2014; 155: 118-25.

29. Ravelli A, Magni-Manzoni S, Pistorio A, et al. Preliminary diagnostic guidelines for macrophage activation syndrome complicating systemic juvenile idiopathic arthritis. J Pediatr 2005; 146: 598-604.

30. Chandrakasan S, Filipovich AH. Hemophagocytic lymphohistiocytosis: advances in pathophysiology, diagnosis, and treatment. J Pediatr 2013; 163: 1253-9. 
31. Davì S, Minoia F, Pistorio A, et al. Performance of current guidelines for diagnosis of macrophage activation syndrome complicating systemic juvenile idiopathic arthritis. Arthritis Rheumatol 2014; 66: 2871-80.

32. Janka GE. Familial and acquired haemophagocytic lymphohistiocytosis. Eur J Pediatr 2007; 166: 95-109.

33. Gupta A, Tyrrell P, Valani R, Benseler S, Abdelhaleem M Weitzman S. Experience with haemophagocytic lymphohistiocytosis/macrophage activation syndrome at a single institution. J Pediatr Hematol Oncol 2009; 31: 81-4.

34. Ravelli A, Grom AA, Behrens EM, Cron RQ. Macrophage activation syndrome as part of systemic juvenile idiopathic arthritis: diagnosis, genetics, pathophysiology and treatment. Genes Immun 2012; 13: 289-98.

35. Hadchouel M, Prieur AM, Griscelli C. Acute hemorrhagic, hepatic, and neurologic manifestations in juvenile rheumatoid arthritis: possible relationship to drugs or infection. J Pediatr 1985; 106: 561-6.

36. Emmenegger U, Frey U, Reimers A, et al. Hyperferritinemia as indicator for intravenous immunoglobulin treatment in reactive macrophage activation syndromes. Am J Hematol 2001; 68: 4-10.

37. Ravelli A, Viola S, De Benedetti F, Magni-Manzoni S, Tzialla C, Martini A. Dramatic efficacy of cyclosporine A in macrophage activation syndrome. Clin Exp Rheumatol 2001; 19: 108.

38. Miettunen PM, Narendran A, Jayanthan A, Behrens EM, Cron RQ. Successful treatment of severe paediatric rheumatic disease-associated macrophage activation syndrome with interleukin-1 inhibition following conventional immunosuppressive therapy: case series with 12 patients. Rheumatology (Oxford) 2011; 50: 417-9.

39. Lis K, Kuzawińska O, Bałkowiec-Iskra E. Tumor necrosis factor inhibitors - state of knowledge. Arch Med Sci 2014; 10: 1175-85.

40. Prahalad S, Bove KE, Dickens D, Lovell DJ, Grom AA Etanercept in the treatment of macrophage activation syndrome. J Rheumatol 2001; 28: 2120-4.

41. Murdaca G, Spanò F, Contatore $M$, et al. Infection risk associated with anti-TNF-alpha agents: a review. Expert Opin Drug Saf 2015; 14: 571-82.

42. Murdaca G, Colombo BM, Puppo F. Anti-TNF-alpha inhibitors: a new therapeutic approach for inflammatory immune-mediated diseases: an update upon efficacy and adverse events. Int J Immunopathol Pharmacol 2009; 22: 557-65.

43. Ramanan AV, Schneider R. Macrophage activation syndrome following initiation of etanercept in a child with systemic onset juvenile rheumatoid arthritis. J Rheumatol 2003; 30: 401-3.

44. Trottestam H, Berglöf E, Horne A, et al. Risk factors for early death in children with haemophagocytic lymphohistiocytosis. Acta Paediatr 2012; 101: 313-8.

45. Dao AT, Luong VT, Nguyen TT, et al. Risk factors for early fatal outcomes among children with hemophagocytic lymphohistiocytosis $(\mathrm{HLH})$ : a single-institution case-series in Vietnam. Pediatr Hematol Oncol 2013; 31: 271-81.

46. Park HS, Kim DY, Lee JH, et al. Clinical features of adult patients with secondary haemophagocytic lymphohistiocytosis from causes other than lymphoma: an analysis of treatment outcome and prognostic factors. Ann Hematol 2012; 91: 897-904.

47. Li J, Wang Q, Zheng W, et al. Hemophagocytic lymphohistiocytosis: clinical analysis of 103 adult patients. Medicine (Baltimore) 2014; 93: 100-5.

48. Minoia F, Davì S, Horne A, et al. Clinical features, treatment and outcome of macrophage activation syndrome complicating systemic juvenile idiopathic arthritis A multinational, multicenter study of 362 patients. Arthritis Rheumatol 2014; 66: 3160-9. 